\title{
Lymphovascular invasion is a high risk factor for stage I/II colorectal cancer: a systematic review and meta-analysis
}

\author{
Hang Yuan ${ }^{1,2, *}$, Quanjin Dong ${ }^{1, *}$, Bo'an Zheng ${ }^{1}$, Xinye $\mathrm{Hu}^{1}{ }^{1}$, Jian-Bo $\mathrm{Xu}^{3}$ and Shiliang \\ $\mathbf{T u}^{1}$ \\ ${ }^{1}$ The Surgical Department of Coloproctology, Zhejiang Provincial People's Hospital, Hangzhou, China \\ 2 Nanjing Medical University, Nanjing, China \\ ${ }^{3}$ Department of Hepatobiliary Surgery, Huai'an First People's Hospital, Nanjing Medical University, Huai'an City, China \\ * These authors have contributed equally to this work \\ Correspondence to: Jian-Bo XU, email: dr_jianbo@163.com \\ Shiliang Tu, email: yuanhang1981@126.com \\ Keywords: lymphovascular invasion, survival, stage I/II, colorectal cancer, meta-analysis \\ Received: January 04, $2017 \quad$ Accepted: February 08, $2017 \quad$ Published: February 16, 2017
}

Copyright: Yuan et al. This is an open-access article distributed under the terms of the Creative Commons Attribution License 3.0 (CC BY 3.0), which permits unrestricted use, distribution, and reproduction in any medium, provided the original author and source are credited.

\section{ABSTRACT}

The prognostic value of lymphovascular invasion (LVI) in stage I/II colorectal cancer (CRC) does not reach a consensus. To systematically assess prognostic significance of LVI, databases of PubMed, Web of Science, and Embase were searched from inception up to 10 Dec 2016. The pooled hazard ratio (HR) and $95 \%$ confidence intervals (CI) were used to determine the prognostic effects. Nineteen relevant studies including 9881 total patients were enrolled. Our results showed that LVI is significantly associated with poor prognosis in overall survival (OS) (HR=2.15, $95 \%$ $C I=1.72-2.68, P<0.01)$ and disease-free survival (DFS) $(H R=1.73,95 \% C I=1.50-$ $1.99, P<0.01)$, which is similar in stage II patients. Further subgroup analysis revealed that the significance of the association between LVI and worse prognosis in CRC patients is not affected by below factors, including geographic setting, LVI positive rate, treatment, tumor site, and quality of the study. The current metaanalysis suggests that LVI may be a poor prognostic factor for stage I/II CRC patients.

\section{INTRODUCTION}

Colorectal cancer (CRC) is one of the leading malignant diseases worldwide. As in other types of cancer, the lymphatic system is the primary pathway of metastasis for CRC. Lymph node status is commonly used to identify a patient's prognosis, tumor stage, and treatment modality [1]. Patients without lymph node metastasis are classified as UICC stage I or II, depending on the infiltration depth. These patients have a favorable prognosis, and adjuvant chemotherapy is restricted to particular risk situations [2]. Nevertheless, approximately $10 \%$ to $20 \%$ of colon cancer cases show an adverse clinical course. To date, there is no generally accepted diagnostic tool available that could predict which of those cases are vulnerable to developing progressive disease.

Lymphovascular invasion (LVI) is thought to be involved the progress of lymphatic metastasis. The
National Comprehensive Cancer Network (NCCN) Guidelines defined several additional factors including LVI status to identify patients at an increased risk for progressive disease in stage II colorectal cancers [2]. However, it remains unclear whether lymphovascular invasion marks a poor prognosis for patients with CRC. Although some researchers have found that patients with LVI positive tumors have a worse prognosis than those with LVI negative tumors [3-5], other investigators have reported that LVI is of no prognostic significance $[6,7]$. It would be of great value to detect whether LVI is associated with a worse prognosis, to be a supplement to existing staging systems to determine whether a patient is suitable for adjuvant treatment [8].The present study was designed to systematically assess the association between LVI and the prognosis of early stage (stage I/II) CRC patients. 
Table 1: demonstrates the detailed process of articles identification and selection.

\begin{tabular}{|c|c|c|c|c|c|c|c|c|c|c|c|c|}
\hline Author & $\begin{array}{l}\text { Published } \\
\text { year }\end{array}$ & Region & $\begin{array}{l}\text { Number } \\
\text { (male/female) }\end{array}$ & \begin{tabular}{|l|} 
Age mean \pm SD $/$ \\
median \\
(range)
\end{tabular} & \begin{tabular}{|l|} 
Follow up(m) \\
mean \pm SD $/$ \\
median \\
$($ range)
\end{tabular} & $\begin{array}{l}\text { Tumor } \\
\text { site }\end{array}$ & $\begin{array}{l}\text { Number } \\
\text { LVI+ } \\
(\%)\end{array}$ & nCRT & pCRT & $\begin{array}{l}\text { TNM } \\
\text { stage }\end{array}$ & Outcome & $\mathbf{S Q}^{\mathrm{a}}$ \\
\hline Ghosh & 2016 & Australia & $690(393 / 297)$ & NR & $53.5(34-65)$ & $\mathrm{C}$ & 209(30.3) & NR & NR & II & DFS & 5 \\
\hline Nikberg & 2016 & Sweden & $2649(\mathrm{NA})$ & NA & NA & $\mathrm{R}$ & $387(14.6)$ & $\mathrm{P}$ & $\mathrm{P}$ & II & DFS & NA \\
\hline Zhang & 2016 & China & $333(188 / 145)$ & $63(17-86)$ & $52.23 \pm 29.7$ & $\mathrm{C}$ & $40(12.0)$ & $\mathrm{N}$ & $\mathrm{P}$ & II & OS & 8 \\
\hline Peng & 2014 & Australia & $458(252 / 206)$ & $73(23-97)$ & $62.4(1.3-126)$ & $\mathrm{C}$ & $115(25.1)$ & $\mathrm{N}$ & $\mathrm{P}$ & II & OS & 8 \\
\hline Patel & 2014 & US & $175(95 / 80)$ & $65(24-89)$ & 720 & $\mathrm{R}$ & $24(13.7)$ & $\mathrm{N}$ & $\mathrm{N}$ & I & OS & 6 \\
\hline $\mathrm{Du}$ & 2014 & China & $145(84 / 61)$ & $69(21-82)$ & $68.5(6-120)$ & $\mathrm{C}$ & $10(6.9)$ & $\mathrm{N}$ & $\mathrm{N}$ & $\mathrm{I} / \mathrm{II}$ & DFS & 8 \\
\hline Lin & 2014 & Taiwan & $962(612 / 350)$ & $71.8(24-107)$ & $60.2(4-106)$ & $\mathrm{CR}$ & $50(5.2)$ & $\mathrm{N}$ & $\mathrm{N}$ & II & DFS & 7 \\
\hline Artac & 2014 & Turkey & $554(332 / 222)$ & $62(26-88)$ & NR & $\mathrm{C}$ & $107(19.3)$ & $\mathrm{N}$ & $\mathrm{P}$ & II & DFS & 7 \\
\hline Venook & 2013 & US & $690(360 / 330)$ & NR & NR & $\mathrm{C}$ & $78(11.3)$ & NR & $\mathrm{P}$ & II & DFS & 5 \\
\hline Betge & 2012 & Austria & $120(61 / 59)$ & $71.2(33.4-85.2)$ & $83(1-180)$ & $\mathrm{CR}$ & $26(21.7)$ & $\mathrm{N}$ & NR & II & OS/DFS & 7 \\
\hline Barresi & 2012 & Italy & $82(45 / 37)$ & $70(48-89)$ & NR & $\mathrm{CR}$ & $23(28.0)$ & $\mathrm{N}$ & $\mathrm{N}$ & I & OS & 5 \\
\hline Choi & 2010 & Hong Kong & $664(385 / 279)$ & $70(27-96)$ & $44(12-104)$ & $\mathrm{CR}$ & $88(13.3)$ & NR & $\mathrm{P}$ & II & DFS & 7 \\
\hline Lim & 2010 & Korea & 903(NR) & NR & $87.5(3-120)$ & $\mathrm{CR}$ & $95(10.5)$ & $\mathrm{N}$ & $\mathrm{P}$ & II & OS/DFS & 6 \\
\hline Huh & 2010 & Korea & $341(209 / 132)$ & $63.1(22-85)$ & $57.6(0.4-106.2)$ & $\mathrm{CR}$ & $44(12.9)$ & $\mathrm{N}$ & $\mathrm{P}$ & II & DFS & 6 \\
\hline Lin CC & 2009 & Taiwan & $375(274 / 101)$ & $68.3 \pm 12.1$ & $48.5(0.7-96.6)$ & $\mathrm{C}$ & $22(5.9)$ & NR & $\mathrm{P}$ & II & DFS & 7 \\
\hline Earle & 2009 & US & $258(139 / 119)$ & NR & NR & $\mathrm{C}$ & $63(24.4)$ & $\mathrm{N}$ & $\mathrm{P}$ & II & OS & 6 \\
\hline Lee & 2006 & Korea & $121(89 / 32)$ & $57.7(28-80)$ & NR & $\mathrm{CR}$ & $25(12.9)$ & NR & $\mathrm{P}$ & $\mathrm{I} / \mathrm{II}$ & DFS & 6 \\
\hline Law & 2005 & Hong Kong & $224(141 / 83)$ & $69(27-89)$ & NR & $\mathrm{R}$ & $29(12.9)$ & NR & NR & II & OS/DFS & 6 \\
\hline Lennon & 2003 & US & $137(79 / 39)$ & $70(36-90)$ & $72(36-108)$ & $\mathrm{C}$ & $34(24.8)$ & NR & NR & II & OS & 4 \\
\hline
\end{tabular}

AJCC American Joint Committee on Cancer, R rectum, C colon, CR colorectum, DFS disease-free survival, N none of patients accept the therapy, nCRT neoadjuvant chemoradiotherapy, NR not reported, NA not access, OS overall survival, P part of patients accept the therapy, pCRT postoperative chemoradiotherapy, LVI+ the colorectal cancer patient with lymphovascular invasion positive, SD standard deviation, SQ score of study quality,

${ }^{a}$ Study quality was judged based on the Newcastle-Ottawa Scale

\section{RESULTS}

\section{Search results}

A total of 939 studies were retrieved from the database search, of which 513 studies were excluded as duplicates, 557 as inappropriate publication types, insufficient data or unrelated to stage I/II CRC. 79 fulltext publications were left over to assess the eligibility. One study failed to get full-text was included due to a great number of sample size and sufficient data calculated from abstract [9]. Eventually, 19 articles met the inclusion criteria and were included in the analysis [7, 9-26]. Figure 1 demonstrates the detailed process of articles identification and selection.

\section{Baseline characteristics of included studies}

Overall, 9881 stage I/II CRC patients were included. A summary of the characteristics of all included studies were exhibited in Table 1. Among the included 19 articles with sample sizes ranging from 82 to 2649 patients $($ median $=341)$, 9 studies (4068 patients, $41.17 \%$ ) were based on Asian populations; the remaining 10 studies (5813 patients, $58.83 \%$ ) were performed in non-Asian populations. The incidence of lymphovascular invasion ranges from $5.2 \%$ to $30.3 \%$, and it was significantly higher in non-Asian region than in Asian region $(P<0.05)$. Nine studies included colon cancer [13-16], 3 included rectal cancer and 7 included total colorectal cancer (without distinguishing colon and rectal cancer) [13-16]. The study quality scores, evaluated by the NOS, ranged from 5 to 8 (with a mean of 6.3), except one study that could not be analyzed because of only access to abstract [9]. Nine studies reported OS and 13 reported DFS as the prognostic indicator.

\section{Data analysis}

\section{LVI and OS in CRC}

A meta-analysis of 9 studies on OS demonstrated that LVI positive is associated with poor prognosis in CRC patients with stage I/II $(\mathrm{HR}=2.15,95 \% \mathrm{CI}=1.72$ 2.68, $P<0.01$; Figure 2) using a fixed-effect model for no significant heterogeneity observed $\left(I^{2}=46 \%, P=\right.$ $0.06)$. DFS data were calculated from 13 studies by the fixed-effect model. Pooled analysis showed a significant 
Table 2: Results of overall and subgroup analyses for effects of LVI on overall and disease-free survival in colorectal cancer

\begin{tabular}{|c|c|c|c|c|c|c|c|}
\hline \multirow{2}{*}{ Categories } & \multirow{2}{*}{$N$} & \multirow{2}{*}{ Patients } & \multirow{2}{*}{ Pooled HR(95 \% CI) } & \multirow{2}{*}{$P$ value } & \multicolumn{2}{|c|}{ Heterogeneity } & \multirow{2}{*}{ Model used } \\
\hline & & & & & $I^{2}$ & $P^{*}$ & \\
\hline Overall survival (OS) & 9 & 2690 & $2.39(1.70-3.36)$ & $<0.01$ & 46 & 0.06 & FEM \\
\hline Subgroup 1: Asian & 3 & 1460 & $2.70(1.27-5.73)$ & 0.01 & 82 & $<0.01$ & REM \\
\hline Non-Asian & 6 & 1230 & $2.27(1.56-3.30)$ & $<0.01$ & 0 & 0.61 & REM \\
\hline Subgroup 2: LVI positive rate $>15 \%$ & 5 & 1055 & $2.45(1.64-3.65)$ & $<0.01$ & 0 & 0.63 & REM \\
\hline LVI positive rate $\leq 15 \%$ & 4 & 1635 & $2.38(1.28-4.43)$ & $<0.01$ & 74 & $<0.01$ & REM \\
\hline Subgroup 3: sample size $>200$ & 4 & 1952 & $2.33(1.37-3.96)$ & $<0.01$ & 71 & 0.02 & REM \\
\hline Sample size $\leq 200$ & 5 & 738 & $2.63(1.68-4.10)$ & $<0.01$ & 0 & 0.47 & REM \\
\hline Subgroup 4: colon cancer & 4 & 1186 & $2.99(2.08-4.31)$ & $<0.01$ & 6 & 0.36 & REM \\
\hline Rectal cancer & 2 & 399 & $2.41(0.91-6.32)$ & 0.08 & 53 & 0.14 & REM \\
\hline Colorectal cancer & 3 & 1105 & $1.64(1.10-2.43)$ & 0.02 & 10 & 0.33 & REM \\
\hline Subgroup 5:study quality score $>6$ & 3 & 911 & $2.43(1.22-4.84)$ & 0.01 & 55 & 0.11 & REM \\
\hline Study quality score $\leq 6$ & 6 & 1779 & $2.32(1.54-3.50)$ & $<0.01$ & 42 & 0.12 & REM \\
\hline Disease-free survival (DFS) & 10 & 8438 & $1.73(1.50-1.99)$ & $<0.01$ & 6 & 0.38 & FEM \\
\hline Subgroup 1: Asian & 8 & 3735 & $1.92(1.57-2.34)$ & $<0.01$ & 0 & 0.56 & FEM \\
\hline Non-Asian & 5 & 4703 & $1.55(1.27-1.90)$ & $<0.01$ & 17 & 0.30 & FEM \\
\hline Subgroup 2: LVI positive rate $>15 \%$ & 4 & 1485 & $1.91(1.34-2.72)$ & $<0.01$ & 17 & 0.30 & FEM \\
\hline LVI positive rate $\leq 15 \%$ & 9 & 6953 & $1.69(1.45-1.98)$ & $<0.01$ & 9 & 0.36 & FEM \\
\hline Subgroup 3: sample size $>200$ & 10 & 8052 & $1.73(1.50-2.00)$ & $<0.01$ & 16 & 0.29 & FEM \\
\hline Sample size $\leq 200$ & 3 & 386 & $1.66(0.72-3.83)$ & 0.24 & 4 & 0.35 & FEM \\
\hline Subgroup 4: colon cancer & 5 & 2454 & $1.86(1.35-2.55)$ & $<0.01$ & 11 & 0.34 & REM \\
\hline Rectal cancer & 2 & 2873 & $1.91(0.95-3.82)$ & 0.07 & 70 & 0.07 & REM \\
\hline Colorectal cancer & 6 & 3111 & $1.64(1.39-1.94)$ & $<0.01$ & 0 & 0.51 & REM \\
\hline Subgroup 5:study quality score $>6$ & 5 & 2266 & $2.09(1.57-2.77)$ & $<0.01$ & 0 & 0.57 & FEM \\
\hline Study quality score $\leq 6$ & 7 & 3523 & $1.72(1.41-2.11)$ & $<0.01$ & 8 & 0.37 & FEM \\
\hline
\end{tabular}

FEM fixed-effect model, REM random-effect model, HR hazard ratio, $\mathrm{N}$ number of studies, pCRT postoperative chemoradiotherapy, $P^{*} P$ value of Q test for heterogeneity test, 95\%CI 95\%confidence interval, LVI lymphovascular invasion

association between LVI and DFS (HR $=1.73,95 \%$ $\mathrm{CI}=1.50-1.99, P<0.01$; Figure 3$)$ with no significant heterogeneity observed $\left(I^{2}=6 \%, P=0.38\right)$.

To distinguish between stage I and II, subgroup analysis by stage of TNM was conducted. In stage I group, only OS data were available. The result showed LVI positive was not associated with poor OS using a random-effect model $(\mathrm{HR}=2.16,95 \% \mathrm{CI}$ : 0.90-5.16, $P=$ 0.08). However, LVI predicted poor OS and DFS in stage II group using a random-effect model (OS: HR $=2.45$, $95 \%$ CI: $1.65-3.64, P<0.01$; DFS: HR $=1.71,95 \%$ CI: $1.48-1.98, P<0.01)$.

Furthermore we performed other subgroup analysis by district (Asian vs. non-Asian patients), LVI positive rate ( $\leq 15$ vs. $>15 \%$ ), sample sizes ( $\leq 190 v s .>200)$, tumor site (colon vs. rectum vs. colorectum) and study quality ( $\leq 6 \mathrm{vs}$. $>6)$, neither of which alter the prognostic role of LVI in OS/DFS. (Table 2)

\section{Evaluation of heterogeneity}

Because of a relative higher $I^{2}$ value for heterogeneity found in OS among the included studies $\left(I^{2}\right.$ $=46 \%, p<0.01)$, the Galbraith plot test was performed to detect the potential source of heterogeneity. The result demonstrated that there was no specific study could be the major source of heterogeneity (Figure 4).

\section{Cumulative meta-analysis}

Cumulative meta-analysis was performed by ordering the included studies based on publication year. The results of cumulative meta-analysis indicated the correlation between LVI and prognosis of colorectal cancer (OS and DFS) in chronologic order (Figure 5). The 95\% CIs have become narrower with increased sample sizes, indicating that the accuracy of the estimates was increasing by the continuous inclusion of studies. 


\section{Sensitivity analysis and publication bias}

Sensitivity analysis was carried out on OS and DFS to assess the stability of the results by sequentially excluding each study in one turn. In present analysis, no study could possibly affect the pooled risk estimate (Figure 6).

Meanwhile, visual assessment of funnel plots (Figure 7), as well as Begg's (Figure 8) and Egger's test (Figure 9) on OS and DFS were performed to assess the publication bias of the included researches. No significant asymmetrical distributions were observed in both groups. No evidence of publication bias was detected by Begg's and Egger's test (OS: $P=0.754, P=0.291$; DFS: $P=$ $0.583, P=0.254$ respectively). Three possible missing studies in OS group and two in DFS group were identified by the trim-and-fill method using fixed-effect model (Figure 10). These missing studies would not change the trend of the results, so our results were reliable. (OS: HR $=1.742,95 \%$ CI: $1.434-2.115$; DFS: $\mathrm{HR}=1.705,95 \%$ CI: 1.482-1.961).

\section{DISCUSSION}

Adjuvant chemotherapy remains controversial in early stage (stage I/II) colorectal cancer, especially who

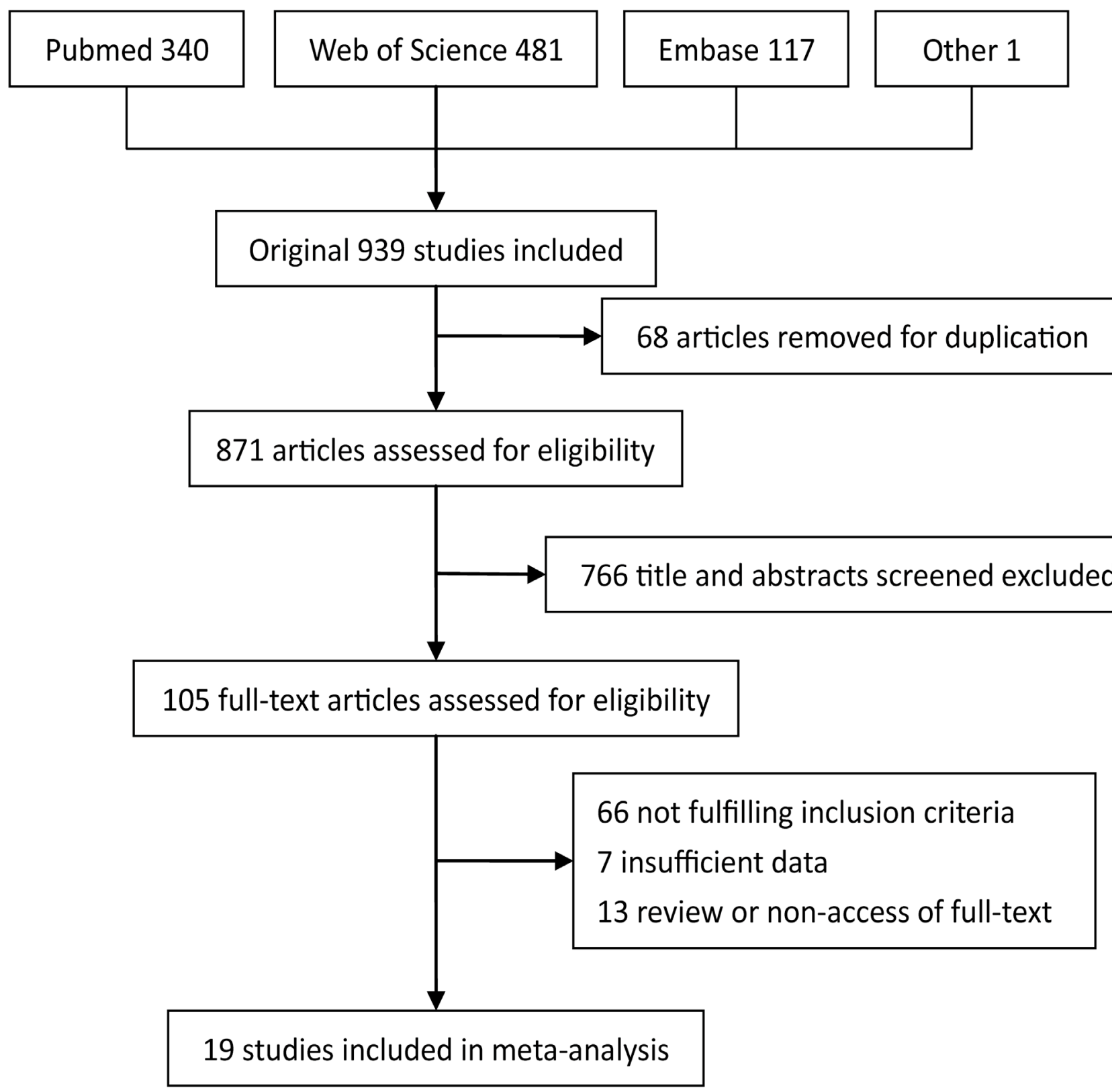

Figure 1: Flow diagram of literature search and study selection. 
would benefit from adjuvant chemotherapy [27, 28]. Uncertainty on the benefit of adjuvant chemotherapy in patients with early stage disease is owing to the fact that which patients at high risk of recurrence are unknown [29]. Hence identification of high-risk stage I/II colorectal cancer patients becomes a clinical concern.

A massive of clinicopathologic features have been associated with a high risk of recurrence and death: tumor stage T4, small number of lymph nodes retrieved, poor differentiation, bowel obstruction, extensive intratumoral necrosis, emergency setting, positive LVI or perineural invasion, and elevated preoperative CEA [30-33]. According to the NCCN guidelines, high risk features for rectal cancer include positive margins, lymphovascular invasion, poorly differentiated tumors, or sm3 invasion. Moreover, poorly differentiated histology, lymphovascular invasion, bowel obstruction, $<12$ lymph nodes examined, perineural invasion, localized perforation, or close, indeterminate, or positive margins are considered as high risks for colon cancer(see at www.NCCN.org). From the list above, LVI tends to be an important prognosis predictor after resection of early stage CRC. However, there are no data in high-risk stage II patients that correlate risk features and selection of chemotherapy. The benefit of adjuvant chemotherapy does not improve survival by more than $5 \%[2,34]$. There is no consensus on the necessity for adjuvant chemotherapy in patients with high-risk stage II cancer [22, 35, 36], whereas most clinicians in China tend to use it for them. In early stage CRC, conflicting study results and insufficient high level evidence regarding the association between LVI and survival data make it necessary to perform a quantitative meta-analysis.

To the best of our knowledge, the present metaanalysis is the first study to provide a system review and meta-analysis on prognostic significance of LVI in early stage (stage I/II) CRC. The included 19 studies and

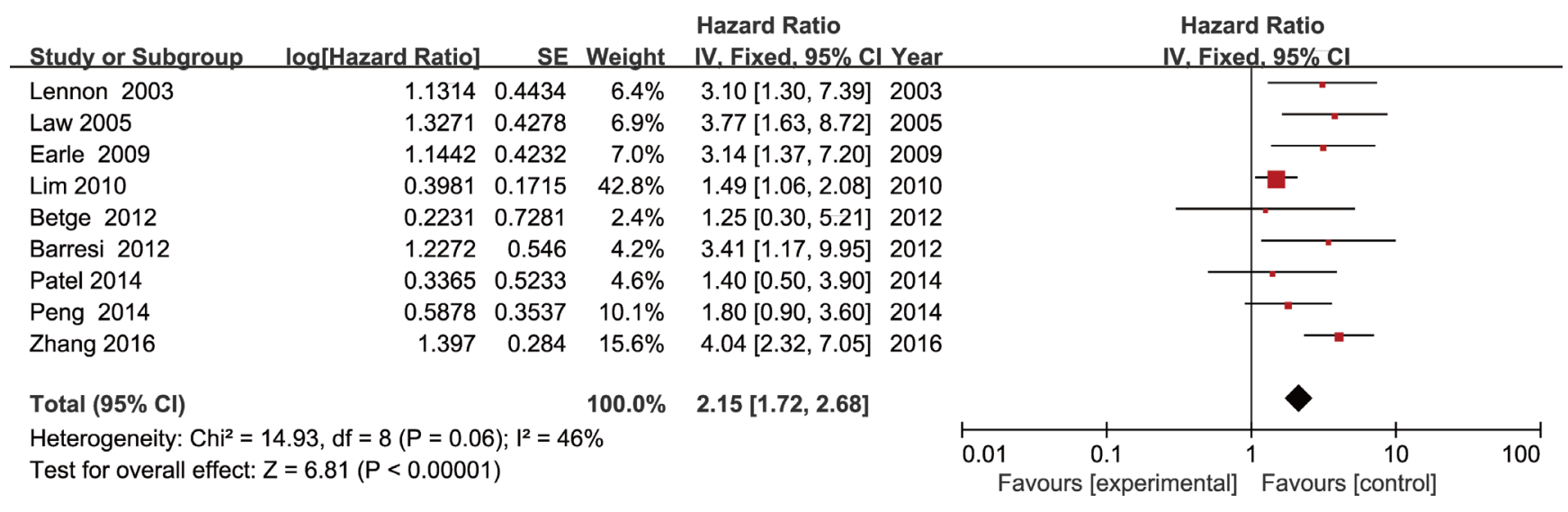

Figure 2: Forest plot of the hazard ratio for the association of lymphovascular invasion with overall survival in colorectal cancer patients.

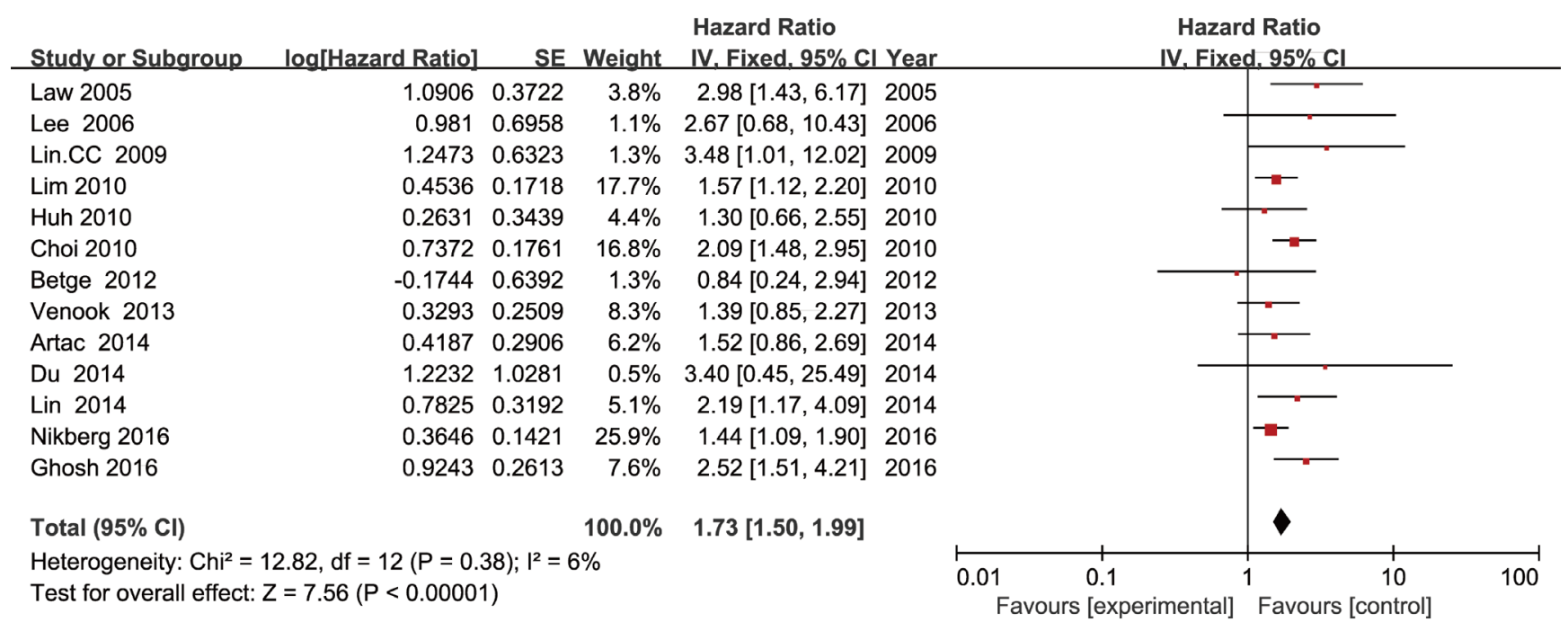

Figure 3: Forest plot of the hazard ratio for the association of lymphovascular invasion with disease free survival in colorectal cancer patients. 


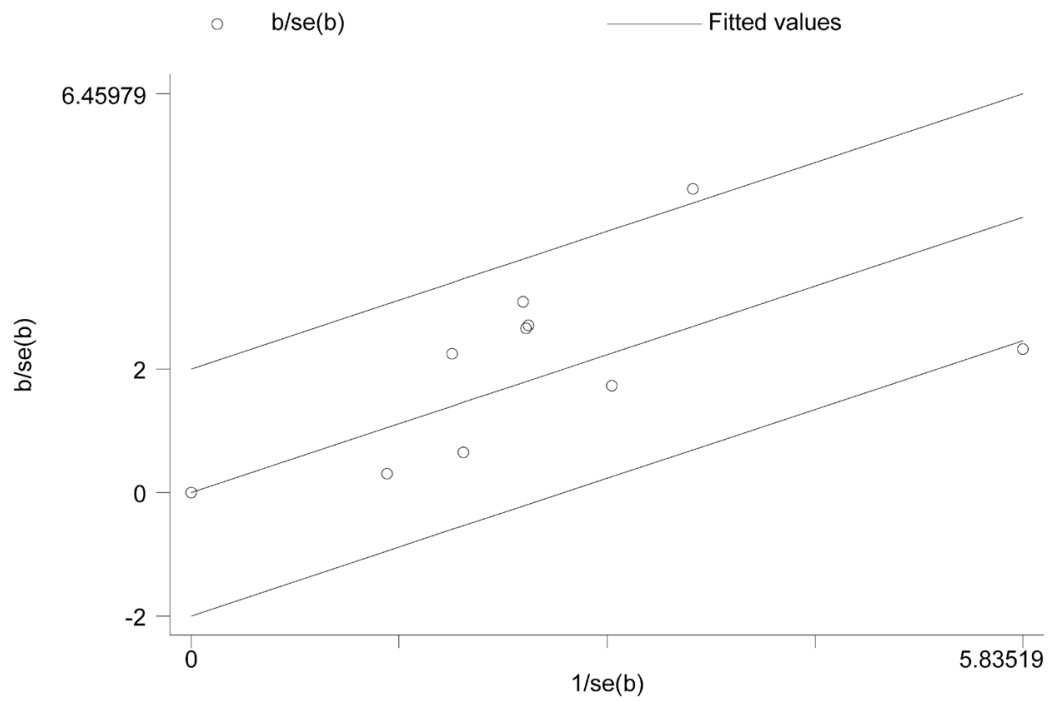

Figure 4: Galbraith plot analysis in overall survival.

A

Study

ID

ES $(95 \% \mathrm{Cl})$

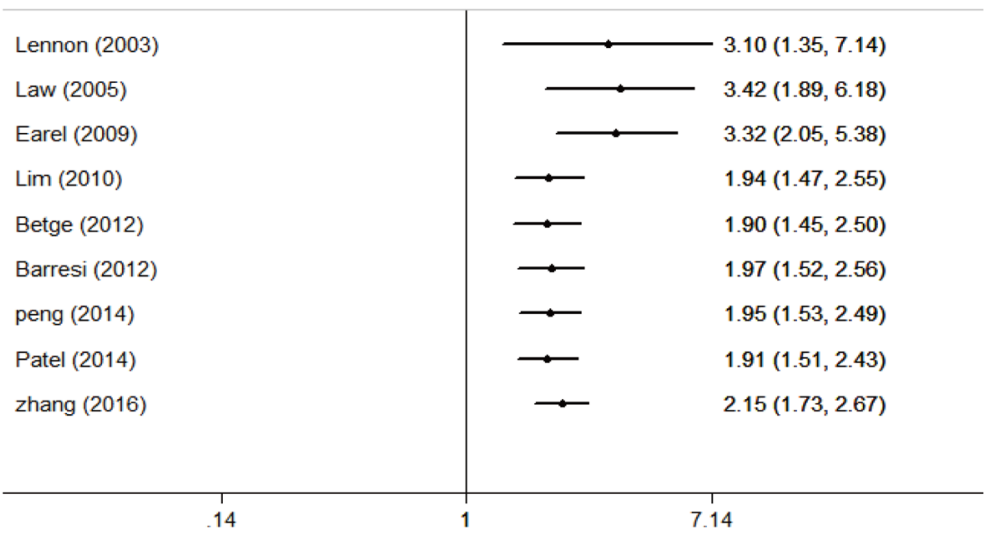

B

Study

ID

ES $(95 \% \mathrm{Cl})$

\begin{tabular}{|c|c|c|}
\hline Law (2005) & $\longrightarrow$ & $-2.98(1.43,6.17)$ \\
\hline Lee (2006) & & $2.90(1.53,5.53)$ \\
\hline Lin C.C (2009) & & $3.02(1.71,5.34)$ \\
\hline Huh (2010) & & $2.12(1.37,3.28)$ \\
\hline $\operatorname{Lim}(2010)$ & $\longrightarrow$ & $1.76(1.35,2.30)$ \\
\hline Choi (2010) & $\longrightarrow$ & $1.88(1.52,2.32)$ \\
\hline Betge (2012) & $\rightarrow$ & $1.84(1.49,2.26)$ \\
\hline Venook (2013) & $\longrightarrow$ & $1.76(1.45,2.13)$ \\
\hline Du (2014) & $\longrightarrow$ & $1.77(1.46,2.14)$ \\
\hline Lin (2014) & $\longrightarrow$ & $1.80(1.50,2.16)$ \\
\hline Artac (2014) & $\rightarrow$ & $1.77(1.49,2.11)$ \\
\hline Nikberg (2016) & $\rightarrow$ & $1.67(1.44,1.94)$ \\
\hline Ghosh (2016) & $\rightarrow$ & $1.73(1.50,1.99)$ \\
\hline
\end{tabular}

Figure 5: Forest plot of cumulative meta-analysis of the association of lymphovascular invasion with overall survival (A) and disease free survival $(\mathbf{B})$ in colorectal cancer patients. 
9881 participants significantly enhanced the statistical power and provided more reliable results. Our results demonstrated that LVI has an unfavorable effect on OS and DFS in patients with early stage CRC. Moreover, the prognostic value was not altered by subgroup analysis based on district (Asian vs. non-Asian patients), LVI positive rate $(\leq 15 v s .>15 \%)$, sample sizes $(\leq 190 v s$. $>200$ ), tumor site (colon vs. rectum vs. colorectum) and study quality $(\leq 6$ vs. $>6)$. Postoperative adjuvant chemotherapy has been shown to prolong DFS or/and

A

Meta-analysis estimates, given named study is omitted I Lower Cl Limit I Estimate Ipper Cl Limit

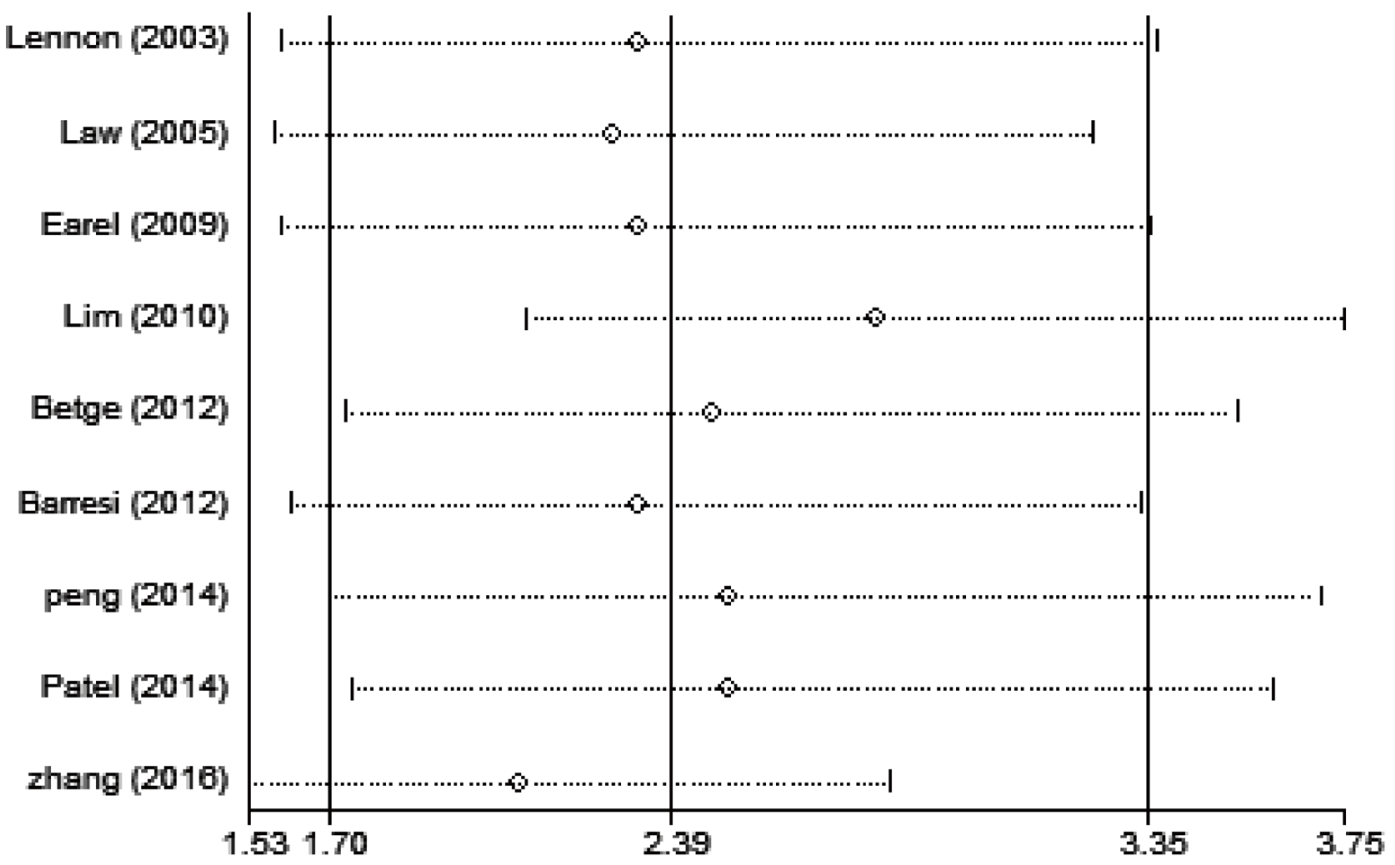

B

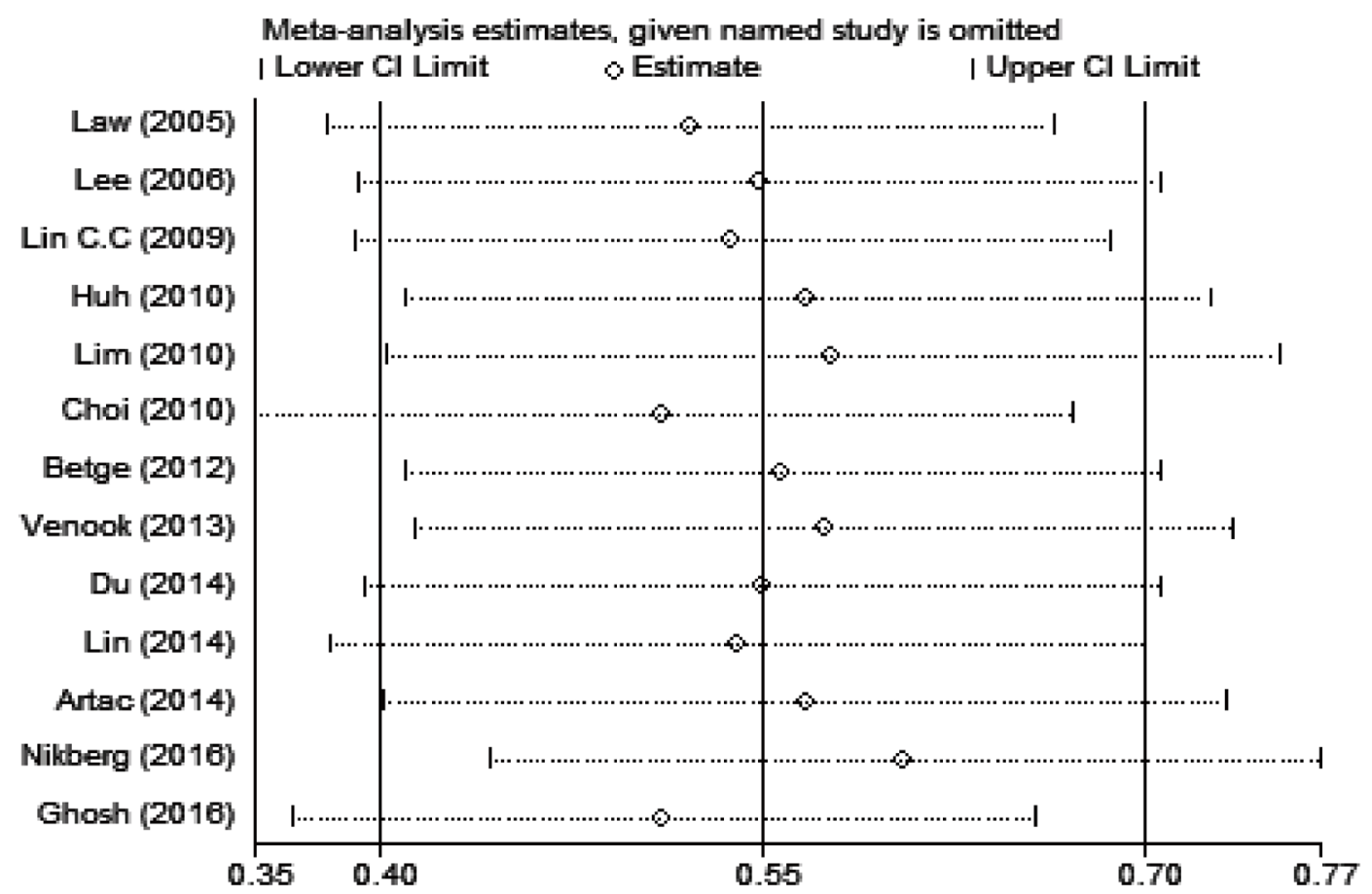

Figure 6: The results of sensitivity analysis of overall survival (A) and disease free survival (B) showing the effect of each study on the overall estimate by sequentially excluding one study in one turn. 
OS in some stage II patients [34, 37], besides NCCN guidelines recommend patients with high-risk stage II colorectal cancer should be considered for adjuvant chemotherapy. Thus it is reasonable to consider adjuvant chemotherapy for stage II patients in LVI positive status. The current NCCN Guidelines have not identified stage I patients who have a high risk of recurrence and this stage patients are not recommended for adjuvant chemotherapy. We suggest imposing stricter surveillance on stage I patients in LVI positive status.

Although Artac M et al. suggested that LVI was not an independent risk factor for survival [7]. A potential

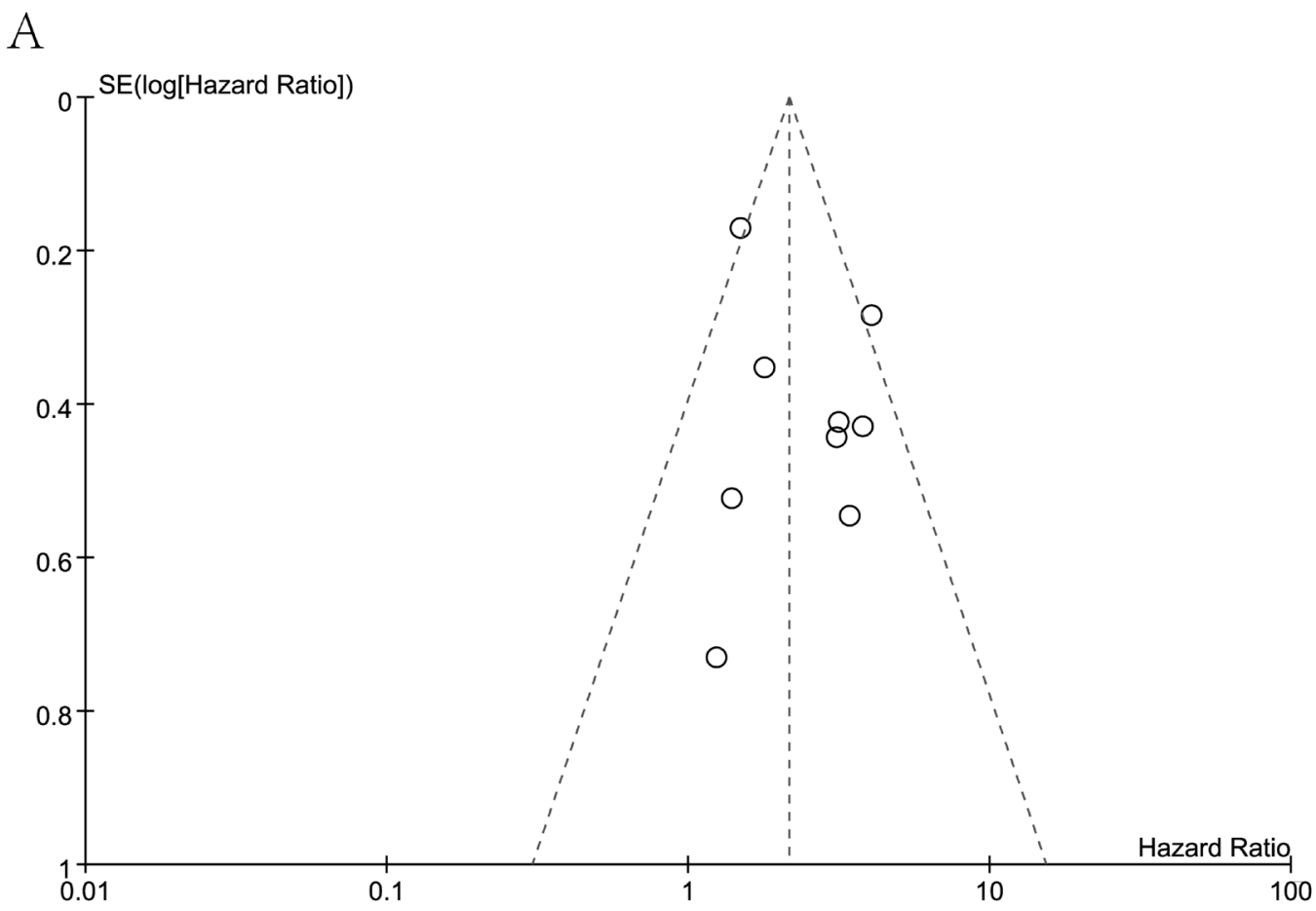

B

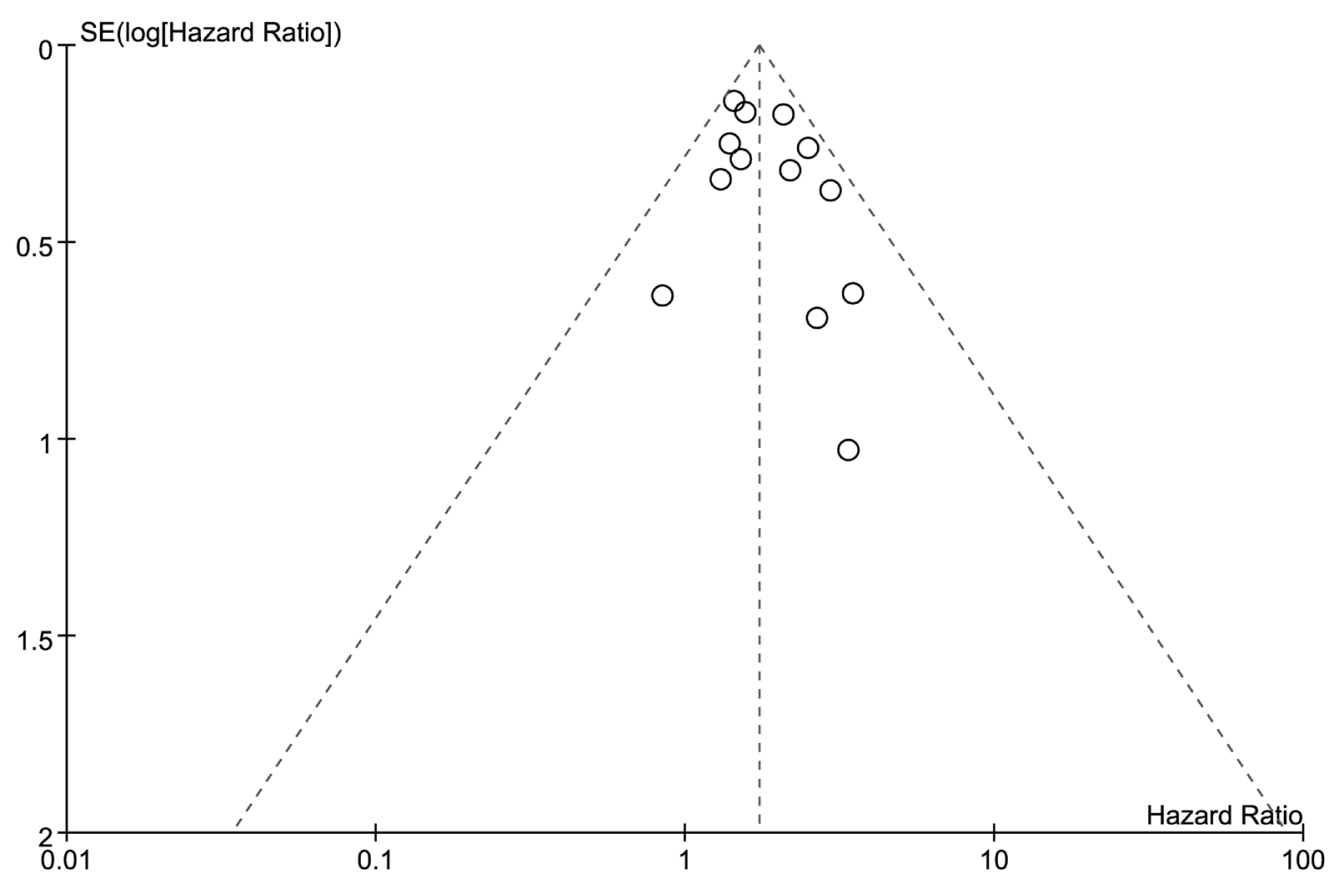

Figure 7: Funnel plot analysis. A. Funnel plot analysis of 9 studies on overall survival. B. Funnel plot analysis of 13 studies on disease free survival. 
value of LVI may be useful in identifying tumors with occult lymph node metastasis [38, 39], for high-risk patients with node negative (stage I/II) tumors warranting adjuvant chemotherapy [32, 40]. As we known, 12 lymph nodes or more must be surgically resected to achieve accurate staging [41]. Lymph node harvest is influenced by many factors, such as the extent of surgical resection, recovery from the resected specimen, and counts of microscopic slides [42, 43]. Twelve-node harvest is sometimes difficult to achieve in daily surgical practice, thus will result in stage migration. Because LVI correlates well with the status of lymph node metastasis and disease staging [21, 44], which make it possible to be a supplement for those understaged patients.
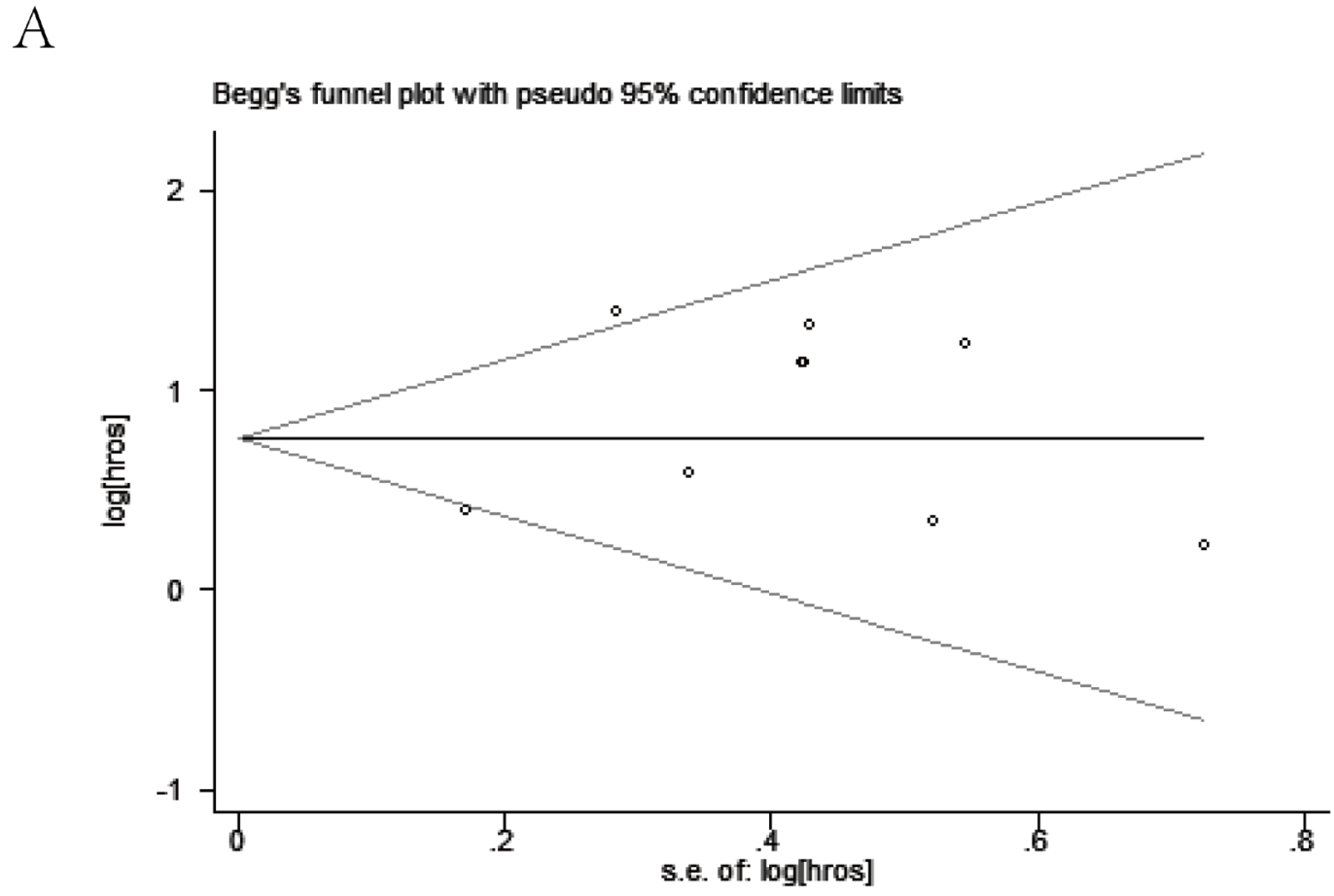

$\mathrm{B}$

\section{Begg's funnel plot with pseudo $95 \%$ confidence limits}

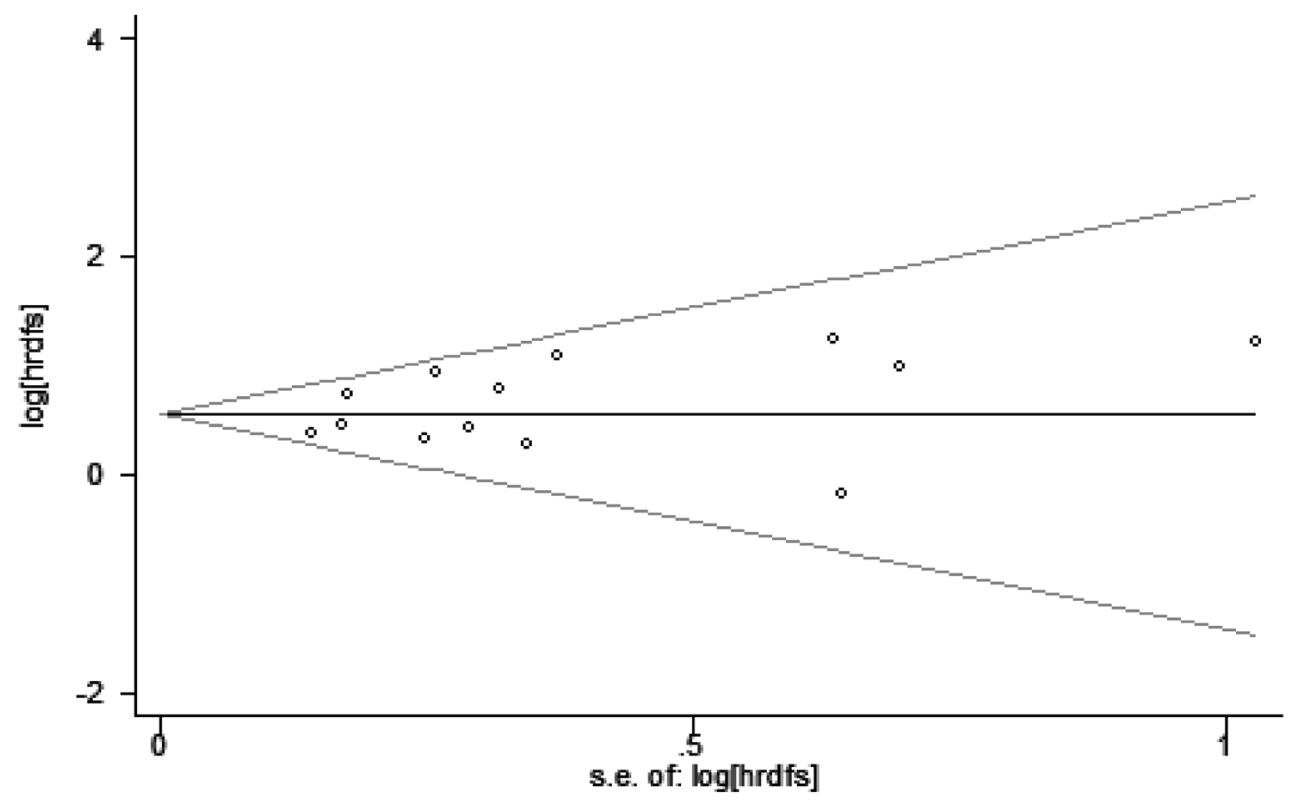

Figure 8: Begg's funnel plot on overall survival (A) and disease free survival (B). 
The incidence of LVI reported in the present study ranged from $5.2 \%$ to $30.3 \%$. The figure was significantly higher in non-Asian region than in Asian region $(p<$ $0.05)$, and the difference in geographic setting had not been reported previously. The wide variation in LVI positive rates may due to many factors, including different geographic setting, differences in the characteristics of tumors, different criteria for LVI presence, and variations in the use of special stains or immunohistochemical (IHC) staining. Furthermore, the College of American Pathologists' consensus statement did not recommend the use of any special stains or immunohistochemical stains

A

Egger's publication bias plot

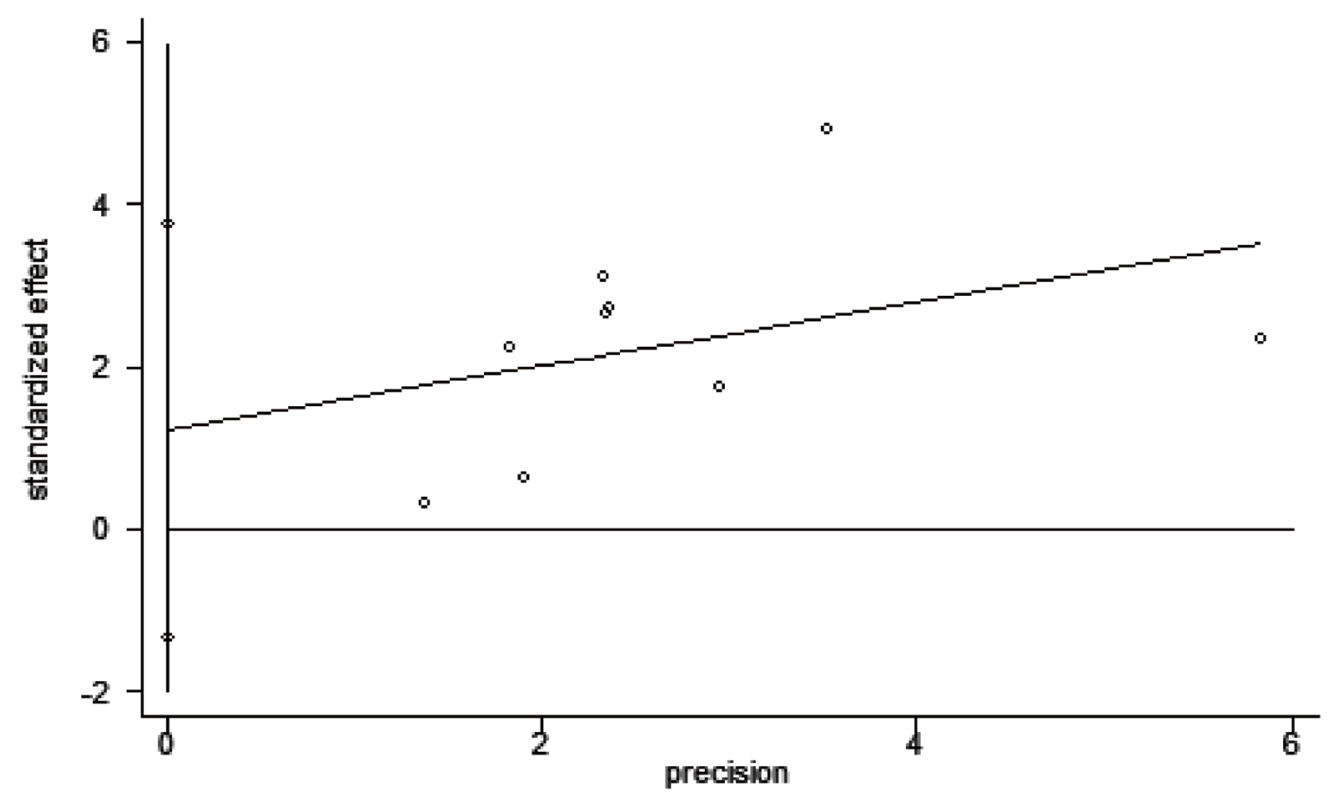

B

Egger's publication bias plot

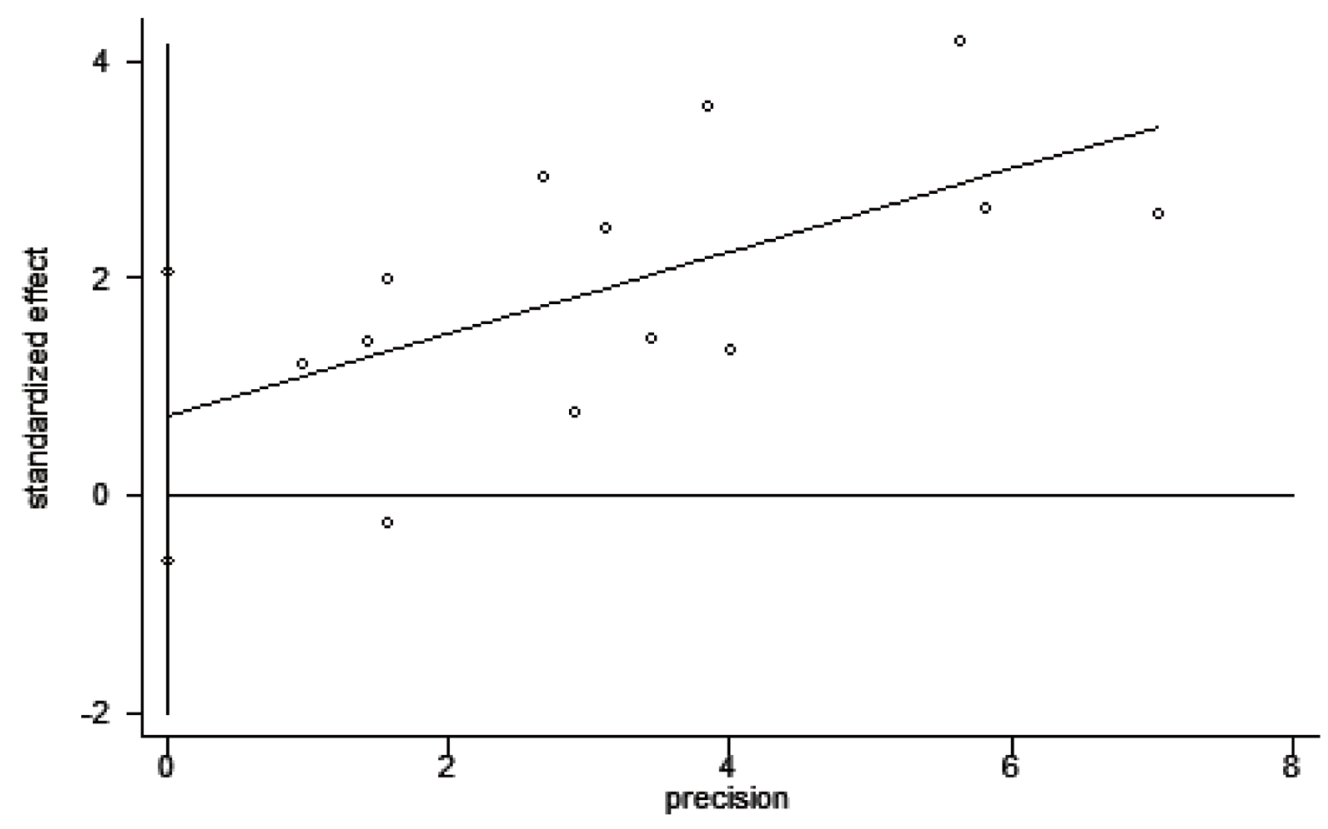

Figure 9: Egger's publication bias plot on overall survival (A) and disease free survival (B). 
to diagnose vessel invasion [45]. The status of LVI was mainly assessed by conventional hematoxylin and eosin (H\&E) staining method in the included studies. One major challenge of this method is that the identification of LVI is subjective and inconsistency [46]. Interobserver variability in diagnosis of LVI was substantial on H\&E slides and did not improve upon use of IHC staining for CD31 and D2-40 [47]. On the contrary, some investigators added IHC staining to improve accuracy rate $[10,48]$.
Another problem with H\&E staining method is hard to distinguish lymphatic vessels invasion from blood vessel invasion (BVI) [46]. In the present study, we combined blood vessel invasion and lymphatic vessels invasion into lymphovascular invasion. We were aware that a study by Liang $\mathrm{P}$ reported that only lymphatic vessels invasion is associated with lymph node metastasis, and BVI is associated with distant recurrence in the manner of immunohistology [48].

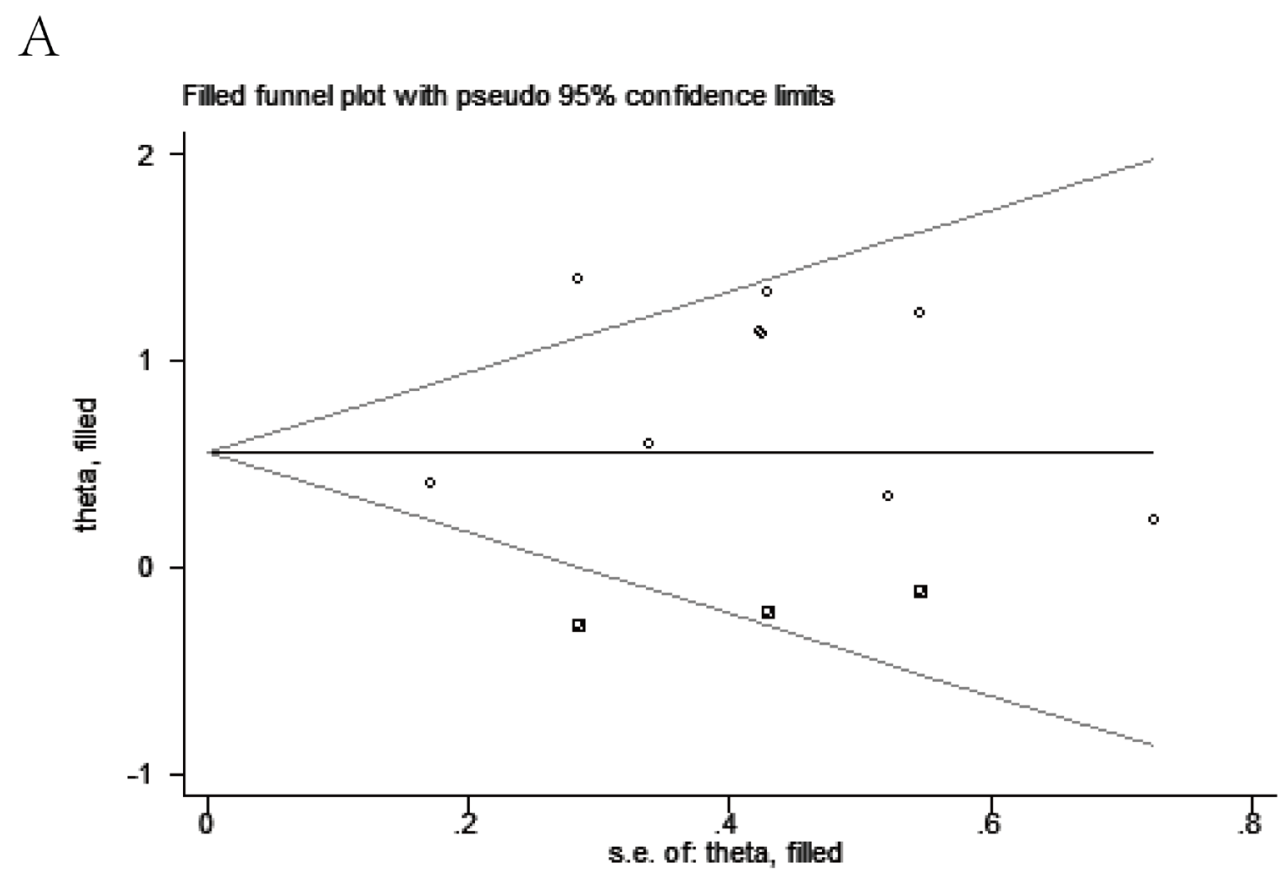

B

Filled funnel plot with pseudo $95 \%$ confidence limits

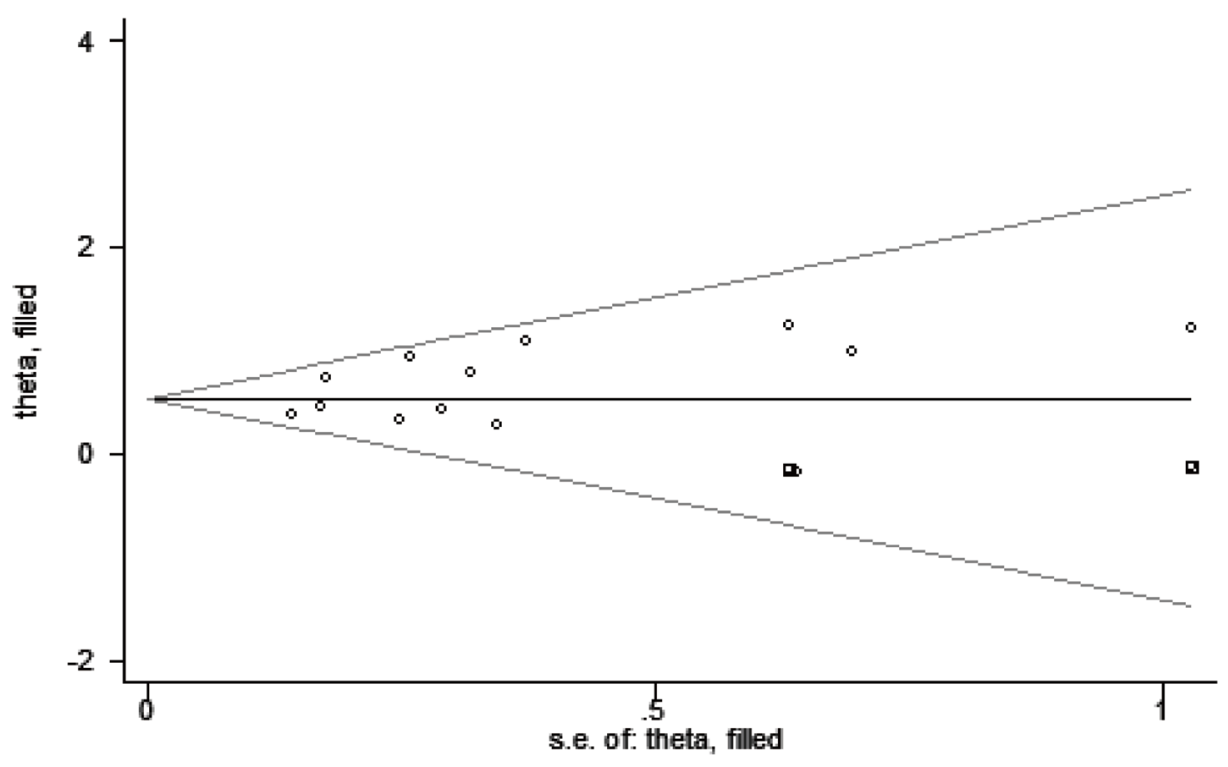

Figure 10: Trim-and-fill funnel plot on overall survival (A) and disease free survival (B). 
Several potential limitations affect the results of this meta-analysis. First, all included studies were observational studies, and some of the sample sizes were relatively small. Second, several studies were excluded due to insufficient data to determine the correlation coefficients. One study included was unable to access full-text with sufficient data to calculate from abstract, but we could not get more detail information [9]. Finally, rare study compared the effect of adjuvant chemotherapy in the stage II patients with LVI positive status. More randomized controlled trials (RCTs) should be performed to validate the benefit form adjuvant chemotherapy for stage I/II CRC patients with LVI positive.

\section{MATERIALS AND METHODS}

\section{Literature search}

A systematic search of the PubMed, Web of Science, and Embase databases was performed to identify all relevant articles published up to 10 Dec 2016 with the limits of English. The following Medical Subject Heading $(\mathrm{MeSH})$ terms or keywords were used: "colorectal neoplasms [MeSH Terms] OR colonic neoplasms [MeSH Terms] OR rectal neoplasms [MeSH Terms]" AND "lymphovascular invasion OR lymphovascular permeation". Moreover, we also check for potentially relevant studies through screening the references of the relevant articles.

\section{Inclusion criteria}

All studies were required to meet the following criteria: (1) the diagnosis of CRC and LVI were based on pathological examination (2) the assessment of the relationships between PVI and the prognosis of CRC patients with stage I/II was reported with overall survival (OS) or/and disease-free survival (DFS), and (3) a hazard ratio (HR) was reported with $95 \%$ confidence interval (CI) or had sufficient data to estimate the HR and $95 \%$ $\mathrm{CI}$ if not directly presented. When results reported from the same patient population, the most recent study or the largest dataset was included.

Abstracts and reports from meetings were excluded. Articles in which the outcomes of interest were not reported or from which it was impossible to calculate outcomes from the original data were also excluded.

\section{Data extraction and quality assessment}

Two authors (H. Yuan and J.B. Xu) independently reviewed each eligible study and extracted the data. If any disagreements existed, they were resolved by discussion.
Data retrieved from the articles included the first author's name, publication year, patient characteristics(number, sex, age, duration of follow-up, community), tumor site, LVI positive rate, study design, TNM staging, treatment characteristics [neoadjuvant chemoradiotherapy (nCRT) and postoperative chemoradiotherapy (pCRT)], and outcomes (OS and DFS). The quality assessment of including studies was based on the criteria of the Newcastle-Ottawa Quality Assessment scale (NOS) [49]. The study with NOS scores $>6$ was regarded as highquality studies.

\section{Statistical analysis}

Meta-analysis was performed in line with the PRISMA guidelines [50]. Pool meta-analysis for OS/DFS was performed by using the Review Manager 5.3 software. The pooled HR and $95 \%$ CI were calculated using the method of inverse variance and the $P$ value threshold was set at 0.05 . Heterogeneity was assessed by a chi-squarebased Q statistical test and the $I^{2}$ value. When $P$ was < 0.10 or/and the $I^{2}$ value was $>50 \%$, it meant significant heterogeneity between the studies and a random-effect model could be used; otherwise, a fixed-effect model was used [51]. Subgroup analysis, sensitivity analysis, publication bias and meta regression were performed using STATA 12.0 software.

Publication bias was assessed using a funnel plot. Subgroup analyses were performed by geographic setting, treatment, TNM staging, tumor site, LVI positive rate, and study quality. The difference of the incidence of LVI between in non-Asian region and in Asian region was performed by independent T-test.

\section{CONCLUSIONS}

In conclusion, this meta-analysis indicated that LVI is a poor prognostic factor for stage I/II CRC patients. Stage II patients with LVI positive should be considered for treatment with effective adjuvant therapies, and stricter surveillance may be imposed on stage I patients in LVI positive status.

\section{Abbreviations}

LVI (lymphovascular invasion); CRC (colorectal cancer); OS (overall survival); DFS (disease free survival); HR (hazard ratio); CI (95\% confidence interval).

\section{Authors' contributions}

HY, QJD and SLT conceived of and designed the study. HY and JBX performed the analyses. HY, BAZ, $\mathrm{XYH}$ and JBX prepared all figures and tables. HY and 
JBX wrote the main manuscript. All authors reviewed the manuscript.

\section{ACKNOWLEDGMENTS}

We thank Professor Shaowen Tang (MD, PhD. Department of Epidemiology, Nanjing Medical University) for technical assistance in this analysis.

\section{CONFLICTS OF INTEREST}

The authors have no conflicts of interest to declare.

\section{FUNDING}

This study was supported by Zhejiang province Medical and Health Project (2014KYA024).

\section{REFERENCES}

1. Zlobec I, Lugli A. Prognostic and predictive factors in colorectal cancer. J Clin Pathol. 2008; 61:561-569.

2. NCCN Clinical Practice Guidelines in Oncology (NCCN Guidelines) in Colon Cancer (Version 1.2017). Available at: http://wwwnccnorg/professionals/physician_gls/f_ guidelinesasp. 2017.

3. Talbot IC, Ritchie S, Leighton MH, Hughes AO, Bussey $\mathrm{HJ}$, Morson BC. The clinical significance of invasion of veins by rectal cancer. The British journal of surgery. 1980; 67:439-442.

4. Horn A, Dahl O, Morild I. The role of venous and neural invasion on survival in rectal adenocarcinoma. Dis Colon Rectum. 1990; 33:598-601.

5. Chapuis PH, Dent OF, Fisher R, Newland RC, Pheils MT, Smyth E, Colquhoun K. A multivariate analysis of clinical and pathological variables in prognosis after resection of large bowel cancer. The British journal of surgery. 1985; 72:698-702.

6. Minsky BD, Mies C, Recht A, Rich TA, Chaffey JT. Resectable adenocarcinoma of the rectosigmoid and rectum. II. The influence of blood vessel invasion. Cancer. 1988; 61:1417-1424.

7. Artac M, Turhal NS, Kocer M, Karabulut B, Bozcuk H, Yalcin S, Karaagac M, Gunduz S, Isik N, Uygun K. Do high-risk features support the use of adjuvant chemotherapy in stage II colon cancer? A Turkish Oncology Group study. Tumori. 2014; 100:143-148.

8. Ueno H, Mochizuki H, Shinto E, Hashiguchi Y, Hase $\mathrm{K}$, Talbot IC. Histologic indices in biopsy specimens for estimating the probability of extended local spread in patients with rectal carcinoma. Cancer. 2002; 94:28822891.

9. Nikberg M, Chabok A, Letocha H, Kindler C, Glimelius B,
Smedh K. Lymphovascular and perineural invasion in stage II rectal cancer: a report from the Swedish colorectal cancer registry. Acta oncologica (Stockholm, Sweden). 2016:1-7.

10. Barresi V, Reggiani Bonetti L, Vitarelli E, Di Gregorio C, Ponz de Leon M, Barresi G. Immunohistochemical assessment of lymphovascular invasion in stage I colorectal carcinoma: prognostic relevance and correlation with nodal micrometastases. The American journal of surgical pathology. 2012; 36:66-72.

11. Betge J, Kornprat $\mathrm{P}$, Pollheimer MJ, Lindtner RA, Schlemmer A, Rehak P, Vieth M, Langner C. Tumor budding is an independent predictor of outcome in AJCC/ UICC stage II colorectal cancer. Ann Surg Oncol. 2012; 19:3706-3712.

12. Zhang CD, Wang JN, Sui BQ, Zeng YJ, Chen JQ, Dai DQ. Prognostic and Predictive Model for Stage II Colon Cancer Patients With Nonemergent Surgery: Who Should Receive Adjuvant Chemotherapy? Medicine. 2016;95:e2190.

13. Choi HK, Law WL, Poon JT. The optimal number of lymph nodes examined in stage II colorectal cancer and its impact of on outcomes. BMC Cancer. 2010; 10:267.

14. Du C, Yao Y, Xue W, Zhu WG, Peng Y, Gu J. The expression of chemokine receptors CXCR3 and CXCR4 in predicting postoperative tumour progression in stages I-II colon cancer: a retrospective study. BMJ Open. 2014; 4:e005012.

15. Earle CC, Weiser MR, Ter Veer A, Skibber JM, Wilson J, Rajput A, Wong YN, Benson AB 3rd, Shibata S, Romanus D, Niland J, Schrag D. Effect of lymph node retrieval rates on the utilization of adjuvant chemotherapy in stage II colon cancer. J Surg Oncol. 2009; 100:525-528.

16. Ghosh P, Tie J, Muranyi A, Singh S, Brunhoeber P, Leith K, Bowermaster R, Liao Z, Zhu Y, LaFleur B, Tran B, Desai J, Jones I, et al. Girdin (GIV) Expression as a Prognostic Marker of Recurrence in Mismatch Repair-Proficient Stage II Colon Cancer. Clinical Cancer Research. 2016; 22:34883498.

17. Huh JW, Kim HR, Kim YJ. Prognostic Value of Perineural Invasion in Patients with Stage II Colorectal Cancer. Annals Of Surgical Oncology. 2010; 17:2066-2072.

18. Law WL, Ho JW, Chan R, Au G, Chu KW. Outcome of anterior resection for stage II rectal cancer without radiation: the role of adjuvant chemotherapy. Dis Colon Rectum. 2005; 48:218-226.

19. Lee MR, Hong CW, Yoon SN, Lim SB, Park KJ, Lee MJ, Kim WH, Park JG. Isolated tumor cells in lymph nodes are not a prognostic marker for patients with stage I and stage II colorectal cancer. J Surg Oncol. 2006; 93(1):13-18; discussion 18-19.

20. Lennon AM, Mulcahy HE, Hyland JM, Lowry C, White A, Fennelly D, Murphy JJ, O’Donoghue DP, Sheahan K. Peritoneal involvement in stage II colon cancer. Am J Clin Pathol. 2003; 119:108-113.

21. Lim SB, Yu CS, Jang SJ, Kim TW, Kim JH, Kim JC. 
Prognostic significance of lymphovascular invasion in sporadic colorectal cancer. Dis Colon Rectum. 2010; 53:377-384.

22. Lin CC, Lin JK, Chang SC, Wang HS, Yang SH, Jiang JK, Chen WS, Lin TC. Is adjuvant chemotherapy beneficial to high risk stage II colon cancer? Analysis in a single institute. Int J Colorectal Dis. 2009; 24:665-676.

23. Lin HH, Chang YY, Lin JK, Jiang JK, Lin CC, Lan YT, Yang SH, Wang HS, Chen WS, Lin TC, Chang SC. The role of adjuvant chemotherapy in stage II colorectal cancer patients. Int J Colorectal Dis. 2014; 29:1237-1243.

24. Patel SA, Chen YH, Hornick JL, Catalano P, Nowak JA, Zukerberg LR, Bleday R, Shellito PC, Hong TS, Mamon HJ. Early-stage rectal cancer: clinical and pathologic prognostic markers of time to local recurrence and overall survival after resection. Dis Colon Rectum. 2014; 57:449459.

25. Peng SL, Thomas M, Ruszkiewicz A, Hunter A, Lawrence M, Moore J. Conventional adverse features do not predict response to adjuvant chemotherapy in stage II colon cancer. ANZ J Surg. 2014; 84:837-841.

26. Venook AP, Niedzwiecki D, Lopatin M, Ye X, Lee M, Friedman PN, Frankel W, Clark-Langone K, Millward C, Shak S, Goldberg RM, Mahmoud NN, Warren RS, et al. Biologic determinants of tumor recurrence in stage II colon cancer: validation study of the 12-gene recurrence score in cancer and leukemia group B (CALGB) 9581. Journal of clinical oncology. 2013; 31:1775-1781.

27. Gill S, Loprinzi CL, Sargent DJ, Thome SD, Alberts SR, Haller DG, Benedetti J, Francini G, Shepherd LE, Francois Seitz J, Labianca R, Chen W, Cha SS, et al. Pooled analysis of fluorouracil-based adjuvant therapy for stage II and III colon cancer: who benefits and by how much? Journal of clinical oncology. 2004; 22:1797-1806.

28. Schrag D, Rifas-Shiman S, Saltz L, Bach PB, Begg CB. Adjuvant chemotherapy use for Medicare beneficiaries with stage II colon cancer. Journal of clinical oncology. 2002; 20:3999-4005.

29. Kelley RK, Venook AP. Prognostic and predictive markers in stage II colon cancer: is there a role for gene expression profiling? Clin Colorectal Cancer. 2011; 10:73-80.

30. Merkel S, Wein A, Gunther K, Papadopoulos T, Hohenberger W, Hermanek P. High-risk groups of patients with Stage II colon carcinoma. Cancer. 2001; 92:14351443.

31. Huh JW, Oh BR, Kim HR, Kim YJ. Preoperative carcinoembryonic antigen level as an independent prognostic factor in potentially curative colon cancer. J Surg Oncol. 2010; 101:396-400.

32. Quah HM, Chou JF, Gonen M, Shia J, Schrag D, Landmann RG, Guillem JG, Paty PB, Temple LK, Wong WD, Weiser MR. Identification of patients with high-risk stage II colon cancer for adjuvant therapy. Dis Colon Rectum. 2008; 51:503-507.
33. Tsai HL, Cheng KI, Lu CY, Kuo CH, Ma CJ, Wu JY, Chai CY, Hsieh JS, Wang JY. Prognostic significance of depth of invasion, vascular invasion and numbers of lymph node retrievals in combination for patients with stage II colorectal cancer undergoing radical resection. J Surg Oncol. 2008; 97:383-387.

34. Figueredo A, Charette ML, Maroun J, Brouwers MC, Zuraw L. Adjuvant therapy for stage II colon cancer: a systematic review from the Cancer Care Ontario Program in evidence-based care's gastrointestinal cancer disease site group. Journal of clinical oncology. 2004; 22:3395-3407.

35. Gray R, Barnwell J, McConkey C, Hills RK, Williams NS, Kerr DJ. Adjuvant chemotherapy versus observation in patients with colorectal cancer: a randomised study. Lancet (London, England). 2007; 370:2020-2029.

36. Tournigand C, de Gramont A. Chemotherapy: Is adjuvant chemotherapy an option for stage II colon cancer? Nature reviews Clinical oncology. 2011; 8:574-576.

37. Wu X, Zhang J, He X, Wang C, Lian L, Liu H, Wang J, Lan P. Postoperative adjuvant chemotherapy for stage II colorectal cancer: a systematic review of 12 randomized controlled trials. Journal of gastrointestinal surgery. 2012; 16:646-655.

38. Wasif N, Faries MB, Saha S, Turner RR, Wiese D, McCarter MD, Shen P, Stojadinovic A, Bilchik AJ. Predictors of occult nodal metastasis in colon cancer: results from a prospective multicenter trial. Surgery. 2010; 147:352-357.

39. Yasuda K, Inomata M, Shiromizu A, Shiraishi N, Higashi $\mathrm{H}$, Kitano S. Risk factors for occult lymph node metastasis of colorectal cancer invading the submucosa and indications for endoscopic mucosal resection. Dis Colon Rectum. 2007; 50:1370-1376.

40. Gertler R, Rosenberg R, Schuster T, Friess H. Defining a high-risk subgroup with colon cancer stages I and II for possible adjuvant therapy. European journal of cancer (Oxford, England : 1990). 2009; 45:2992-2999.

41. Swanson RS, Compton CC, Stewart AK, Bland KI. The prognosis of T3N0 colon cancer is dependent on the number of lymph nodes examined. Ann Surg Oncol. 2003; 10:6571.

42. Morris EJ, Maughan NJ, Forman D, Quirke P. Identifying stage III colorectal cancer patients: the influence of the patient, surgeon, and pathologist. Journal of clinical oncology. 2007; 25:2573-2579.

43. Baxter NN, Virnig DJ, Rothenberger DA, Morris AM, Jessurun J, Virnig BA. Lymph node evaluation in colorectal cancer patients: a population-based study. Journal of the National Cancer Institute. 2005; 97:219-225.

44. Akagi Y, Adachi Y, Ohchi T, Kinugasa T, Shirouzu K. Prognostic Impact of Lymphatic Invasion of Colorectal Cancer: A Single-center Analysis of 1,616 Patients Over 24 Years. Anticancer Research. 2013; 33:2965-2970.

45. Compton CC, Fielding LP, Burgart LJ, Conley B, Cooper 
HS, Hamilton SR, Hammond ME, Henson DE, Hutter RV, Nagle RB, Nielsen ML, Sargent DJ, Taylor CR, et al. Prognostic factors in colorectal cancer. College of American Pathologists Consensus Statement 1999. Arch Pathol Lab Med. 2000; 124:979-994.

46. Compton C, Fenoglio-Preiser CM, Pettigrew N, Fielding LP. American Joint Committee on Cancer Prognostic Factors Consensus Conference: Colorectal Working Group. Cancer. 2000; 88:1739-1757.

47. Harris EI, Lewin DN, Wang HL, Lauwers GY, Srivastava A, Shyr Y, Shakhtour B, Revetta F, Washington MK. Lymphovascular invasion in colorectal cancer: an interobserver variability study. The American journal of surgical pathology. 2008; 32:1816-1821.

48. Liang P, Nakada I, Hong JW, Tabuchi T, Motohashi G, Takemura A, Nakachi T, Kasuga T, Tabuchi T. Prognostic significance of immunohistochemically detected blood and lymphatic vessel invasion in colorectal carcinoma: its impact on prognosis. Ann Surg Oncol. 2007; 14:470-477.

49. Stang A. Critical evaluation of the Newcastle-Ottawa scale for the assessment of the quality of nonrandomized studies in meta-analyses. European journal of epidemiology. 2010; 25:603-605.

50. Moher D LA, Tetzlaff J, Altman DG. PRISMA Group. Preferred reporting items for systematic reviews and metaanalyses: the PRISMA statement. Ann Intern Med. 2009; 151:264-269.

51. Higgins JP, Thompson SG, Deeks JJ, Altman DG. Measuring inconsistency in meta-analyses. BMJ open. $2003 ; 327: 557-560$. 